\title{
Tabanidae (Diptera) no dossel da floresta amazônica atraídos por luz e descrição de machos de três espécies
}

\author{
Tiago Kütter KROLOW ${ }^{1}$, Augusto Loureiro HENRIQUES² ${ }^{2}$ José Albertino RAFAEL ${ }^{3}$
}

\begin{abstract}
RESUMO
Foram realizadas coletas de tabanídeos a 40 metros de altura, em uma torre metálica, na Estação Experimental de Silvicultura Tropical, Amazonas, Brasil. As coletas foram realizadas de janeiro a dezembro de 2004, durante três noites de transição lunar minguante/nova de cada mês, das 18 às 6 horas. As mutucas foram capturadas em um lençol iluminado com lâmpada de luz mista de vapor de mercúrio de 250 watts e lâmpada de 20 watts BLB. Foram coletados 216 espécimes, dos quais 135 machos e 81 fêmeas, alocados em 29 espécies. Três machos desconhecidos são descritos pela primeira vez: Catachlorops halteratus Kröber, 1931, Leucotabanus janinae Fairchild, 1970 e Leucotabanus pauculus Fairchild, 1951.
\end{abstract}

PALAVRAS-CHAVE: dossel, floresta amazônica, torre, atrativo luminoso, descrição de machos.

\section{Tabanidae (Diptera) in the canopy of the Amazon rainforest attracted by light and description of males of three species}

\begin{abstract}
Tabanids were collected at a height of 40 meters on a metallic tower, at Estaçáo Experimental de Silvicultura Tropical, Manaus, Amazonas, Brazil. Samples were collected monthly from January to December of 2004, during three nights of lunar transition third quarter moon/ new moon from 06 p.m. to 06 a.m. Horse flies were captured on a vertical sheet illuminated by a 250 -watts mixed mercury vapor light and 20-watts black-light (BLB) lamps. 216 specimens were collected, of which 135 were males and 81 were females belonging to 29 species. Males of three species with unknown males are described for the first time, namely: Catachlorops halteratus Kröber, 1931, Leucotabanus janinae Fairchild, 1970 and Leucotabanus pauculus Fairchild, 1951.
\end{abstract}

KEYWORDS: canopy, Amazon forest, tower, attractive light, description of males.

1 Instituto Nacional de Pesquisas da Amazônia.E-mail: tkkrolow@gmail.com

2 Instituto Nacional de Pesquisas da Amazônia.E-mail: Ioureiro@inpa.gov.br

${ }^{3}$ Instituto Nacional de Pesquisas da Amazônia.E-mail: jarafael@inpa.gov.br 


\section{INTRODUÇÃO}

Os adultos de Tabanidae são conhecidos principalmente pelas fêmeas, tanto por sua importância epidemiológica devido ao hábito hematófago, quanto pela maior frequência de captura. Os machos são florícolas ou nectívoros, pouco representados nas coleçóes e a maioria desconhecidos. Isto pode estar relacionado com a influência dos períodos de floração, com a preferência de voo em estratos arbóreos mais elevados ou por voo em áreas restritas à espera de fêmeas para o acasalamento.

São encontrados nos mais diversos tipos de hábitats e suas preferências são bem definidas por áreas inalteradas, com exceção de algumas espécies, que aparentemente preferem áreas abertas ou hábitats modificados e possuem ampla distribuição geográfica (Fairchild 1981). Diversos estudos demonstram a preferência de algumas espécies de mutucas por diferentes estratos arbóreos (Fairchild 1953; 1986; Chvála e Stary 1967; Roberts 1976; Rafael e Gorayeb 1982; Gorayeb 1999).

As fêmeas são coletadas de forma satisfatória com armadilhas de interceptação de voo, tipo Malaise, armadilha suspensa (Rafael e Gorayeb 1982) e isca equina. Já os machos raramente são coletados com Malaise e nunca com isca animal. A utilização de atrativo luminoso atrai espécimes machos de hábitos diurnos e crepusculares e geralmente fêmeas com hábitos crepusculares ou mesmo diurnos (Frost 1951; Anthony 1960; Philip 1982; Fairchild 1986; Henriques e Rafael 1999).

A diversificação e a integração de diferentes métodos de coleta ampliam as possibilidades de incremento na captura de tabanídeos machos, tanto em abundância quanto em riqueza. Dessa forma, este trabalho apresenta resultados inéditos para este grupo, indicando que algumas espécies habitam o dossel, onde podem se alimentar e copular.

\section{MATERIAL E MÉTODOS}

As coletas foram realizadas em uma torre metálica a 40 metros de altura (Figura 1), localizada em um platô de terra firme, na Estação Experimental de Silvicultura Tropical, Manaus, Amazonas, Brasil (02³5’21”S; 6006'55”W). Ocorreram de janeiro a dezembro de 2004, durante três noites de transição lunar minguante/nova de cada mês, das 18 às 6 horas. A coleta das mutucas foi feita manualmente colocando o frasco mortífero sobre os espécimes pousados no lençol iluminado com lâmpada de luz mista de vapor de mercúrio de 250 watts e lâmpada BLB de 20 watts. A descrição detalhada do método e do local de coleta foi feita no trabalho de Martins et al. (2006). O material estudado está depositado na Coleção de Invertebrados do Instituto Nacional de Pesquisas da Amazônia (INPA).

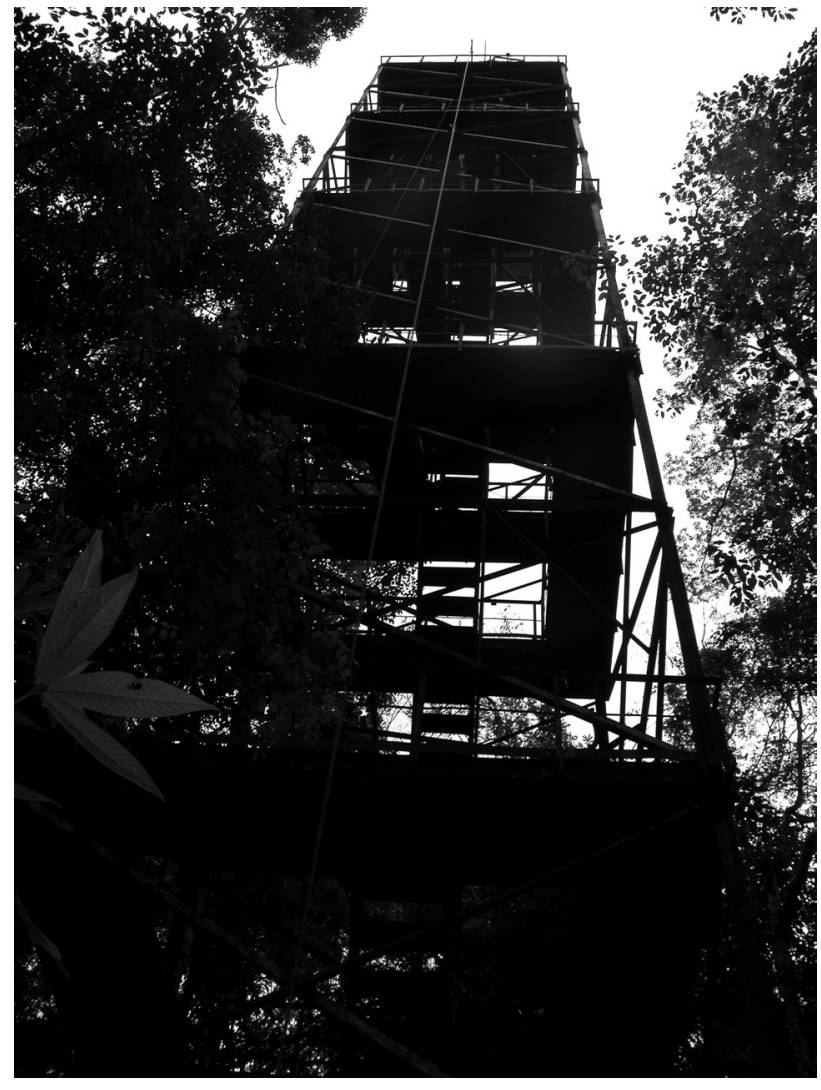

Figura 1 - Torre metálica utilizada para coleta de insetos, Estação Experimental de Silvicultura Tropical, Amazonas, Brasil.

A terminologia morfológica externa segue McAlpine (1981) e Pechuman e Teskey (1981) e a da terminália segue Sinclair et al. (1993). Para a dissecaçáo da terminália foi utilizado o protocolo de Cumming (1992). As variações de medidas sáo apresentadas do valor mínimo para o máximo, onde $\mathrm{X}$ e $\mathrm{N}$ significam, respectivamente, média e número de indivíduos observados.

\section{RESULTADOS}

Foram coletados 216 espécimes, sendo 135 machos e 81 fêmeas, representados por 29 espécies (Tabela 1). Quatro machos desconhecidos são registrados pela primeira vez, dos quais três são descritos abaixo. $\mathrm{O}$ macho de Catachlorops rufescens (Fabricius, 1805), não foi descrito neste trabalho, pois foi objeto de estudo da dissertaçáo de Scherer (2009).

\section{TAXONOMIA}

\section{Catachlorops halteratus Kröber, 1931}

$$
\widehat{\jmath} \text { (Figuras 2-4, 11-12) }
$$

DIAGNOSE: comprimento do corpo sem antenas 12,6 $\mathrm{mm}$, comprimento da asa 11,4 mm. Cabeça, tórax e abdômen 
Tabela 1 - Tabanídeos coletados com armadilha luminosa no dossel a 40 metros do solo em floresta, Reserva Experimental da Silvicultura, Manaus, Amazonas.

\begin{tabular}{|c|c|c|}
\hline Espécies & Machos & Fêmeas \\
\hline Acanthocera gorayebi Henriques \& Rafael, 1992 & 3 & - \\
\hline Acanthocera marginalis Walker, 1854 & 6 & 4 \\
\hline${ }^{\star}$ Catachlorops halteratus Kröber, 1931 & 1 & 1 \\
\hline Catachlorops overali Fairchild \& Rafael, 1985 & 6 & 1 \\
\hline${ }^{*}$ Catacholorops rufescens (Fabricius, 1805) & 11 & 2 \\
\hline Bolbodimyia brunneipennis Stone, 1954 & 3 & - \\
\hline Chlorotabanus inanis (Fabricius, 1787) & 3 & 4 \\
\hline Chrysops incisus Macquart, 1846 & - & 4 \\
\hline Chrysops variegatus (DeGeer, 1776) & - & 1 \\
\hline Dichelacera cervicornis (Fabricius, 1805) & - & 1 \\
\hline Fidena analis (Fabricius, 1805) & 3 & 1 \\
\hline Leucotabanus albovarius (Walker, 1854) & - & 1 \\
\hline Leucotabanus exaestuans (Linnaeus, 1758) & 11 & - \\
\hline *Leucotabanus janinae Fairchild, 1970 & 1 & - \\
\hline *Leucotabanus pauculus Fairchild, 1951 & 20 & 9 \\
\hline *Leucotabanus aff. L. sebastianus Fairchild, 1941 & 4 & 2 \\
\hline Philipotabanus stigmaticalis (Kröber, 1931) & 32 & 26 \\
\hline Poeciloderas quadripunctatus (Fabricius, 1805) & 1 & - \\
\hline Stenotabanus bequaerti Rafael, Fairchild \& Gorayeb, 1982 & - & 1 \\
\hline Stibasoma currani Philip, 1943 & - & 1 \\
\hline Stypommisa captiroptera (Kröber, 1930) & 3 & 3 \\
\hline Stypommisa glandicolor (Lutz, 1912) & 8 & 8 \\
\hline Stypommisa modica (Hine, 1920) & 6 & - \\
\hline Tabanus amapaensis Fairchild, 1961 & 5 & 1 \\
\hline Tabanus occidentalis Linnaeus, 1758 & - & 2 \\
\hline Tabanus piceiventris Rondani, 1848 & 1 & - \\
\hline Tabanus sannio Fairchild, 1956 & - & 1 \\
\hline Tabanus sextriangulus Gorayeb \& Rafael, 1984 & 1 & - \\
\hline Tabanus trivittatus Fabricius, 1805 & 6 & 7 \\
\hline TOTAL & 135 & 81 \\
\hline
\end{tabular}

*espécies com machos não descritos

castanho-escuros com pelos pretos. Antena com a placa basal estreita e alongada, com espinho dorsal proeminente quase alcançando o estilo. Asa preta, exceto por manchas hialinas na base da célula basal radial, na região distal da veia média, e no ápice da asa. Pernas castanho-escuras com pelos pretos.

CABEÇA (Figura 3): olhos glabros, holópticos, bicolores (espécime seco), omatídios maiores castanho-escuros, ocupam a área superior do olho, omatídios menores cinza-escuros ocupam a área inferior. Tubérculo ocelar pouco desenvolvido. Triângulo frontal e subcalo com pruinosidade castanho-escura, glabro. Parafaciália, gena e face com pruinosidade castanho-escura e pelos pretos. Palpo porrecto castanho-escuro com pelos pretos. Antena (Figura 4) concolor ao palpo. Escapo e pedicelo com pelos pretos. Flagelo com a placa basal estreita, alongada e com projeção dorsal proeminente em forma de espinho, quase alcançando o estilo, esta com pelos esparsos. Estilo alongado, aproximadamente uma vez e meia o comprimento da placa basal. Porção distal do último flagelômero com alguns pelos pretos. Probóscide esclerosada, brilhante, com teca e labela pretas.

TÓRAX (Figura 2): mesonoto com tegumento castanhoescuro e escutelo castanho, pruinosidade acinzentada e pelos pretos, exceto a regiáo anterior, com faixa transversal de pelos esbranquiçados, entre os lobos pós-pronotais. Pleura e esterno como o mesonoto, exceto pela pruinosidade cinza acentuada. Pernas castanho-escuras, quase pretas, com pelos pretos, exceto coxas com pruína cinza. Asa preta, exceto por manchas hialinas na base da célula basal radial, na região distal da veia média, e no ápice da asa. Basicosta glabra e pterostigma preto.

ABDÔMEN (Figura 2): tergitos castanhos, quase pretos na margem distal, cobertos de pruína castanha e pelos pretos 
e esbranquiçados. Esternitos semelhantes aos tergitos, exceto pela pruinosidade acinzentada.

TERMINÁLIA: Epândrio, cercos e hipoprocto como na Figura 11. Epândrio afilado na região anterior, dividido em duas peças; alargado a partir dos dois terços distais, onde as peças quase se unem. As peças estão unidas medianamente por uma membrana. Epândrio glabro anteriormente, pilosidade esparsa mediana e densa posteriormente. Cercos ultrapassam a margem distal do hipoprocto, cobertos de pelos longos e densos. Hipoprocto encoberto pelos cercos em vista dorsal, apenas com o esclerito subepandrial aparente. Hipândrio, gonocoxito, gonóstilo e edeago como na Figura 12. Hipândrio + gonocoxitos robusto, mais longo que largo, margem anterior arredondada. Ápice do gonocoxito com pelos delgados e longos na face interna. Base do hipândrio com margem estreita e arredondada. Edeago longo, pontiagudo, com tamanho subigual aos apódemas gonocoxais. Ápice do gonóstilo truncado.

MATERIAL EXAMINADO: BRASIL, Amazonas: Manaus, ZF-2 km 14, Torre, 02³5'21"S; 6006'55”W, 18 21.ii.2004, Luz mista/BL, BLB, lençol, $40 \mathrm{mt}$ alt[ura], col., J.A Rafael, C.S. Motta, F.F. Xavier Filho, A. Silva Filho \& S. Trovisco $\left(1 \bigcirc^{\AA}\right)$.

COMENTÁRIOS: O macho de $C$. halteratus é idêntico à fêmea, exceto pelo dimorfismo sexual característico de Tabanidae, olhos holópticos e palpos porrectos nos machos.

\section{Leucotabanus janinae Fairchild, 1970}

$$
\widehat{\partial} \text { (Figuras 5-7, 13-14) }
$$

DIAGNOSE: comprimento do corpo sem antenas $9,5-$ $10,7 \mathrm{~mm}(\mathrm{~N}=2 ; \mathrm{X}=10,1 \mathrm{~mm})$, comprimento da asa $8,0-8,6$ $\mathrm{mm}(\mathrm{N}=2 ; \mathrm{X}=8,3)$. Antena castanho-alaranjada com pelos pretos. Mesonoto e escutelo cobertos de pruína branco-neve e pelos da mesma cor. Pernas com tíbias bicolores. Asa hialina, com leve escurecimento da célula basal costal, pterostigma castanho-claro. Abdômen castanho-alaranjado com faixas transversais de pelos brancos nos tergitos 2, 4 e 6 .

CABEÇA (Figura 6): olhos compostos glabros, holópticos, bicolores (espécimes seco), omatídios maiores castanhoescuros, ocupam a área superior do olho, omatídios menores cinza-escuros, ocupam a área inferior. Tubérculo ocelar bem desenvolvido com pruína branca. Triângulo frontal castanho, sem pelos. Subcalo com pruína branca, sem pelos. Parafaciália, gena e face com pruinosidade branca e pelos da mesma cor. Palpo castanho-claro, porrecto, com pruinosidade e pilosidade branca. Antena (Figura 7) com escapo e pedicelo castanhoalaranjados com pelos pretos. Flagelo mais alaranjado que o restante da antena, placa basal curta, com ângulo dorsal pouco elevado e pelos pretos na elevaçáo. Estilo longo, mais longo que a placa basal, com pelos pretos esparsos. Probóscide completamente membranosa, preta com pelos da mesma cor.

TÓRAX (Figura 5): tegumento castanho-alaranjado. Escuto e escutelo cobertos por pruinosidade branco-neve e pelos da mesma cor, exceto por alguns pelos pretos na notopleura. Pleura e esterno com pruína e pelos semelhantes aos do escuto. Pernas delgadas. Coxas com pruína e pelos idênticos a pleura, exceto nas proximidades dos trocânteres, mais escuras e com pelos pretos. Trocânteres e fêmures castanho-escuros com pelos pretos. Tíbias (vista dorsal) brancas com pelos brancos, exceto, pelo quarto distal castanho-escuro com pelos pretos. Tíbias (vista ventral) castanho-claras com pelos brancos, exceto pelo quarto distais distal, como em vista dorsal. Tarsos castanhos com pelos pretos. Asa hialina, com escurecimento da célula basal costal. Basicosta castanho-clara com pelos pretos esparsos. Venação alar e pterostigma castanho-claros.

ABDÔMEN (Figura 5): castanho-alaranjado. Tergito 1 com pelos brancos sublaterais e um tufo mediano de pelos pretos. Tergito 2 revestido de pelos brancos. Tergito 3 coberto de pelos pretos, exceto por faixa estreita transversal de pelos brancos na margem posterior. Tergito 4 revestido de pelos brancos. Tergitos 5 e 6 com pelos pretos esparsos, exceto por faixa transversal de pelos brancos na margem posterior. Tergito 7 coberto por pruína branca e pelos brancos. Esternitos 1 e 2 cobertos de pruína e pelos brancos. Esternitos 3-6 cobertos de pelos pretos, exceto por faixa estreita transversal posterior de pelos brancos. Esternito 7 coberto por pruína branca e pelos brancos e pretos mesclados.

TERMINÁLIA: Epândrio, cercos e hipoprocto como na Figura 13. Região anterior do epândrio afilada com ápice arredondado, regiáo posterior alargada. Hipoprocoto triangular, encoberto pelos cercos, exceto pela região mediana e esclerito subepandrial aparentes. Esclerito subepandrial afilado e pontiagudo. Cercos com ápices arredondados, excedendo a porçáo distal do hipoprocto, cobertos de pelos longos e densos. Hipândrio, gonocoxito, gonóstilo e edeago como na Figura 14. Hipândrio + gonocoxitos robusto, mais longo que largo e margem anterior truncada com leve arredondamento nas bases laterais. Gonocoxitos tubulares, com tufo de pelos nas proximidades dos gonóstilos. Edeago longo em forma de "lança", pouco menor que os apódemas gonocoxais.

MATERIAL EXAMINADO: BRASIL, Amazonas: Manaus, ZF-2, Torre, 02³5'21”S; 6006'55”W, 26.x.2003, Arm.[adilha] Luz (lençol), $40 \mathrm{mt}$ alt[ura], col., J.A Rafael, F.F. Xavier Filho \& A. Silva Filho $(1 \overbrace{}^{\Uparrow})$; idem: Itacoatiara, Madeireira Mil, 0245'10"S; 58³9'11"W, 29-30.xi.2005, armadilha luminosa móvel, 00-01hs, J. A. Rafael, R. J. P. Machado \& A. Silva Filho $(1 \overbrace{}^{\Uparrow})$.

COMENTÁRIOS: Externamente o macho de L. janinae é muito semelhante ao de $L$. exaestuans, principalmente pela 
disposição das faixas de pilosidade do abdômen. Os caracteres diferenciais de $L$. exaestuans são: antena mais escura, com estilo quase negro; palpos com pelos pretos densos; mesonoto coberto de pruína acinzentada e pelos castanho-claros; trocânteres e fêmures pretos com pelos pretos; tíbia anterior com metade proximal branca com pelos brancos e metade distal preta com pelos pretos; tíbias mediana e posterior com o terço distal preto com pelos da mesma cor; venaçáo alar e pterostigma mais escuros, quase pretos; abdômen castanhoescuro.

A associação do macho com a fêmea de $L$. janinae é sustentada principalmente por: coloraçáo e forma da antena; padrão de pruinosidade e pilosidade dos palpos e pernas; coloraçáo da venação alar e do pterostigma.

\section{Leucotabanus pauculus Fairchild, 1951}

$$
\widehat{o} \text { (Figuras 8-10, 15-16) }
$$

DIAGNOSE: comprimento do corpo sem antenas 10,0 - 11,3 mm $(\mathrm{N}=3 ; \mathrm{X}=10,4 \mathrm{~mm})$, comprimento da asa $8,5-9,5 \mathrm{~mm}(\mathrm{~N}=3 ; \mathrm{X}=8,9)$. Antena preta, placa basal com ângulo dorsal pouco elevado. Estilo alongado, subigual ao comprimento da placa basal.Tórax com regiáo anterior cinza-azulado, o restante castanho-escuro, exceto por lobo pós-pronotal, notopleura, calo pós-alar e escutelo, todos esbranquiçados. Pernas bicolores, com as tíbias em preto e branco. Asa hialina, com leve escurecimento das células basal costal e costal, pterostigma castanho-escuro. Abdômen com tergitos 1 e 2 castanho-amarelados; a partir do tergito 3 castanho-escuro. Tergitos 2 e 4 com faixas distais transversais de pelos brancos.

CABEÇA (Figura 9): olhos compostos glabros, holópticos, bicolores (espécime seco), omatídios maiores castanhoclaros, ocupam a área superior do olho, omatídios menores cinza-escuro, ocupam a área inferior. Tubérculo ocelar bem desenvolvido. Triângulo frontal castanho-escuro, subcalo castanho-amarelado, ambos sem pelos. Parafaciália, gena e face com pruinosidade esbranquiçada e pelos da mesma cor. Palpo porrecto com pruinosidade branca e pelos brancos, às vezes com alguns pelos pretos na extremidade distal do segundo palpômero. Antena (Figura 10) preta, escapo e pedicelo pretos com pelos da mesma cor. Placa basal com ângulo dorsal pouco elevado. Estilo alongado, subigual ao comprimento da placa basal. Probóscide completamente membranosa, preta com pelos da mesma cor.

TÓRAX (Figura 8): tegumento castanho-escuro. Mesonoto com regiáo anterior cinza-azulado, o restante castanho-escuro, exceto pelo lobo pós-pronotal, notopleura, calo pós-alar e escutelo, todos esbranquiçados. Mesonoto coberto por pelos brancos e pretos mesclados com a acentuação de pelos pretos na notopleura, proximidades do pré-escutelo e base do escutelo. Pleura e esterno com pruína esbranquiçada e pelos brancos, exceto meron com pruinosidade castanhoescura com um pequeno tufo de finos pelos brancos. Pernas delgadas. Coxas mediana e posterior com pruína idêntica a do meron, com pelos pretos. Regiáo proximal da coxa anterior com pruína esbranquiçada e pelos brancos, regiáo distal com pruína castanho-escurecida e pelos pretos. Trocânteres e fêmures pretos com pelos pretos. Tíbias levemente escurecidas na região proximal, regiôes medianas brancas com pelos brancos, quarto distal preto com pelos pretos. Tarsos pretos com pelos da mesma cor. Asa hialina, com leve escurecimento das células basal costal e costal. Basicosta castanho-escura com cerdas pretas. Veias castanhas, sem apêndice na forquilha da $\mathrm{R}_{4+5}$, pterostigma castanho-escuro.

ABDÔMEN (Figura 8): tergitos 1 e 2 castanhoamarelados, tergitos 3-7 castanho-escuros. Tergitos cobertos de pelos pretos, exceto pelo tergito $1 \mathrm{com}$ faixa distal transversal incompleta de pelos brancos e tergitos 2 e 4 com faixa distal transversal completa de pelos brancos. Esternitos $1 \mathrm{e}$ 2 amarelos com pelos brancos, os demais castanho-escuros com pelos pretos.

TERMINÁLIA: Epândrio, cercos e hipoprocto como na Figura 15. Epândrio afilado na regiáo anterior, dividido em duas peças, com alargamento a partir do segundo terço até a extremidade distal. Região posterior do epândrio com uma faixa estreita de pelos nas proximidades dos cercos. Região mediana com alguns pelos esparsos e região posterior glabra. Cercos arredondados e com pilosidade densa, ultrapassando a margem distal do hipoprocto. Hipoprocto quase totalmente coberto pelos cercos, sendo possível a visualização do ápice levemente arredondado e do esclerito subepandrial. Esclerito subepandrial afilado com ápice arredondado. Hipândrio, gonocoxito, gonóstilo e edeago como na Figura 16. Hipândrio + gonocoxitos robusto, mais longo que largo, margem anterior truncada com leve arredondamento nas bases laterais. Gonocoxitos tubulares, com alguns pelos nas proximidades dos gonóstilos. Edeago alongado, com a regiáo anterior tubular e comprimento inferior ao dos apódemas gonocoxais.

MATERIAL EXAMINADO: BRASIL, Amazonas: Manaus, ZF-2 km 14, Torre, 02³5'21"S; 6006'55”W, 20.xi.2003, Arm.[adilha] Luz (lençol), $40 \mathrm{mt}$ alt[ura], col., J.A Rafael, F.F. Xavier Filho \& A. Silva Filho (1 $\left.{ }^{\Uparrow}\right)$; idem, 19-22.iii.2004, Luz mista/BL, BLB, lençol, $40 \mathrm{mt}$ alt[ura], col., J.A Rafael, C.S. Mota, F.F. Xavier Filho, A. Silva Filho \& J.T. Câmara (1ठ̂); idem, 16-19.iv.2004, Luz mista/BL, BLB, lençol, $40 \mathrm{mt}$ alt[ura], col., J.A Rafael, C.S. Mota, A. Silva

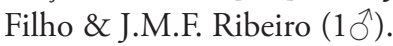

COMENTÁRIOS: As fêmeas de L. janinae, L. pauculus e $L$. exaestuans são semelhantes, entretanto, os machos de $L$. janinae e $L$. exaestuans não possuem o mesmo padrão de coloração de tórax e abdômen de suas respectivas fêmeas, 
ACTA

AMAZONICA
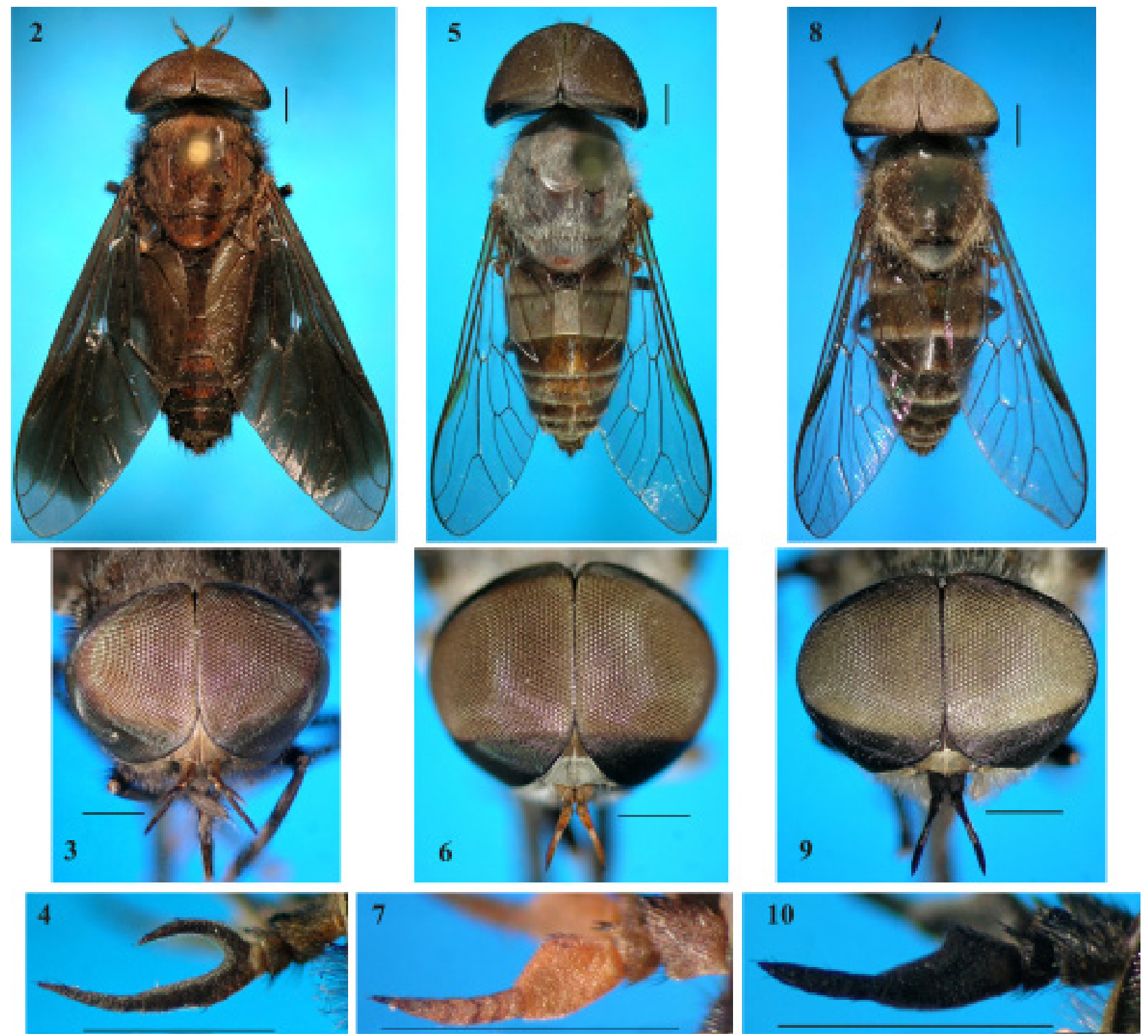

Figuras 2-4 (1 mm) - Catachlorops halteratus Kröber, 1931 ふ, 2. Habitus; 3. Cabeça vista frontal; 4. Antena vista lateral.

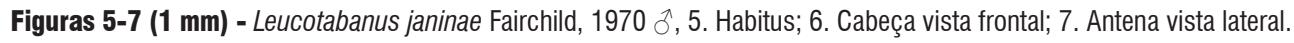

Figuras 8-10 (1 mm) - Leucotabanus pauculus Fairchild, 1951 ๙ิ, 8. Habitus; 9. Cabeça vista frontal; 10. Antena vista lateral. 
11

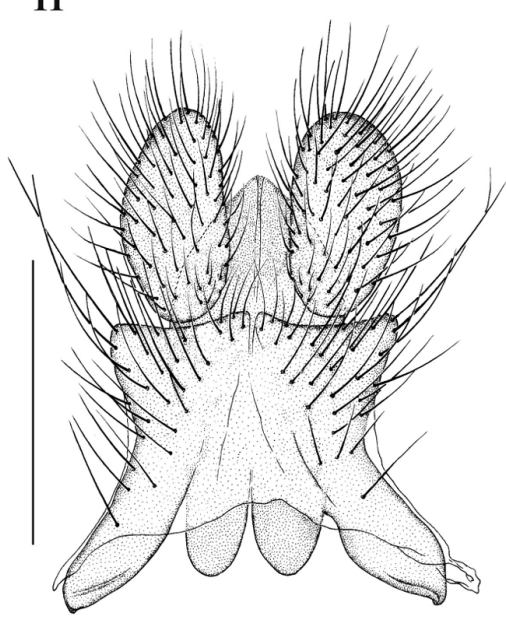

12

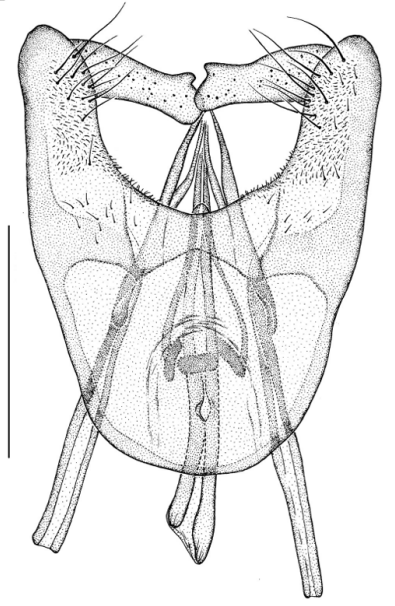

13

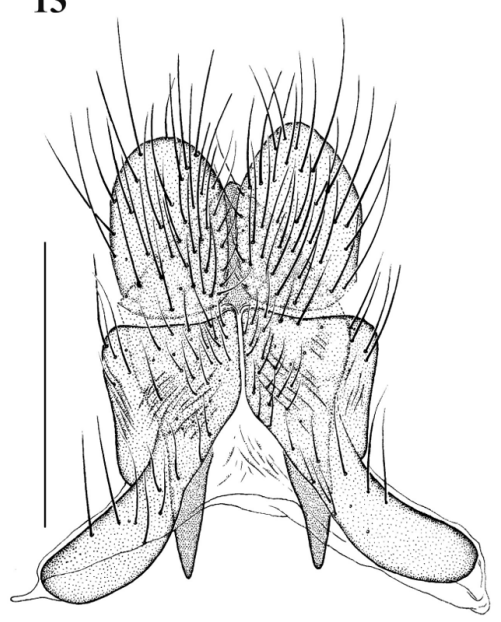

14

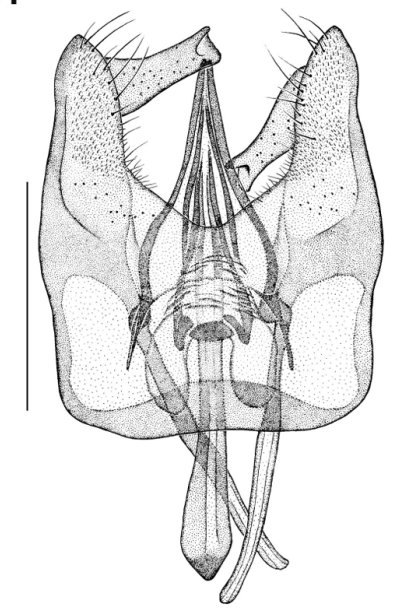

15

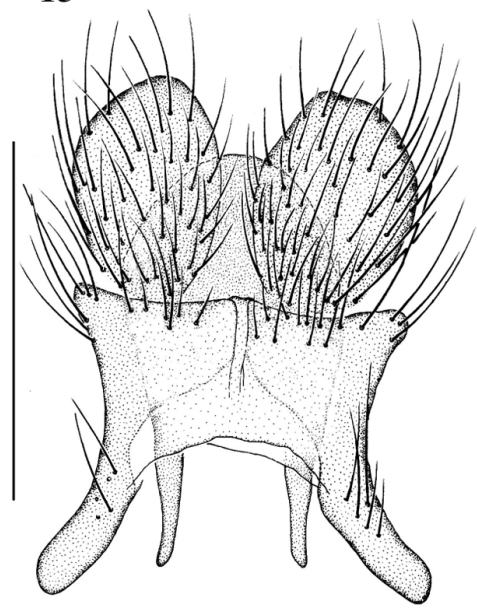

16

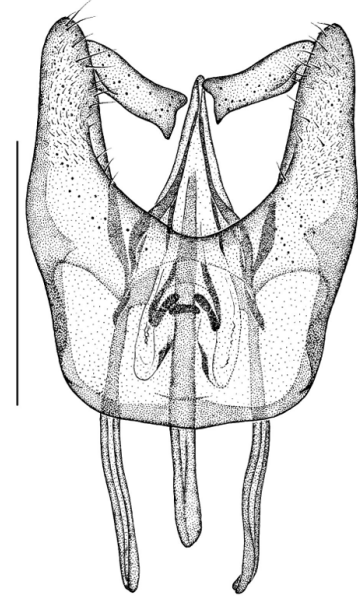

Figuras 11-12 (0,5mm) - Catachlorops halteratus Kröber, 1931 đ̃; 11. Epândrio, cercos e hipoprocto; 12. Hipândrio + gonocoxitos e gonóstilos.

Figuras 13-14 (0,5mm) - Leucotabanus janinae Fairchild, 1970 ; 13. Epândrio, cercos e hipoprocto; 14. Hipândrio + gonocoxitos e gonóstilos.

Figuras 15-16 (0,5mm) - Leucotabanus pauculus Fairchild, 1951 đో; 15. Epândrio, cercos e hipoprocto; 16. Hipândrio + gonocoxitos e gonóstilos.

já que são cobertos de pilosidade esbranquiçada. Enquanto L. pauculus pode ser facilmente associado a sua fêmea, por conservar padróes de coloração e forma da antena, tórax, abdômen e pernas.

\section{DISCUSSÃO}

A maioria das espécies de Tabanidae é coletada nos estratos inferiores de florestas ou em ambientes abertos, sendo normalmente representadas por fêmeas. A coleta de machos nesses ambientes é incipiente, entretanto, no dossel, o atrativo luminoso demonstrou eficácia, pois em um único ponto de amostragem foram coletadas 29 espécies e destas 21 com representantes machos. Isto pode indicar que os machos estâo adaptados a voar no nível ou sobre o dossel durante o dia, onde provavelmente ocorre a cópula, e depois ficam pousados no alto da vegetação.
A coleta de machos com armadilha luminosa não significa que os mesmos tenham atividade noturna, mas que são atraídos pela fonte luminosa quando esta é instalada nas proximidades do local de repouso. A coleta no dossel tem a vantagem de atrair grande quantidade de machos, porque a luz pode se propagar a longas distâncias, sem os obstáculos comuns encontrados quando o mesmo tipo de armadilha é instalado no nível do solo.

Apesar das coletas realizadas neste trabalho se concentrarem em uma área restrita, e com esforço amostral de apenas um ano, o número de espécies coletadas é relativamente alto, se comparado a levantamentos realizados em outras áreas como a Reserva Tambopata, Peru e Parque Nacional do Jaú, Brasil, ambos, com 73 espécies (Wilkerson e Fairchild 1985; Henriques 2004) e Reserva Florestal Adolfo Ducke, Brasil, local com a maior diversidade de mutucas do mundo, 80 espécies (Barbosa et al. 2005) e com grande esforço de coleta há mais de 40 anos. 
A coleta no dossel demonstrou ser eficiente para a complementação de inventários da tabanofauna, pois capturou um número considerável de espécimes machos, não coletados em Malaise, armadilha suspensa ou atração por luz no solo. Barbosa et al. (2005) em um ano de coleta na Reserva Ducke com 15 armadilhas de interceptação de voo, modelo Townes (1972) registraram 7.285 espécimes de mutucas, mas nenhum macho foi capturado. Henriques e Rafael (1999) registraram em nove coletas no Parque Nacional do Jaú, 2.046 espécimes de mutucas, com apenas 37 machos de 15 espécies, para isso, utilizaram vários métodos de coleta, inclusive atração por luz no solo.

Os dados apresentados no presente trabalho contribuem para o melhor conhecimento sobre a bionomia dos tabanídeos na Amazônia, demonstrando que os machos de mutucas, geralmente pouco representados em coleçôes entomológicas, podem ser coletados em maior abundância através da utilização de atrativo luminoso em dossel.

\section{AGRADECIMENTOS}

Aos participantes das coletas na torre da ZF-2, Catarina da Silva Motta, Simone Trovisco, Francisco Felipe Xavier Filho, Alexandre da Silva Filho, Joseleide Teixeira Câmara, Marcelo Cutrim Moreira de Castro, Fábio Godoi, Fabrício Báccaro, Luis de Sales Aquino e Alexandre Ururahy Rodrigues, funcionários ou alunos do INPA.

\section{BIBLIOGRAFIA CITADA}

Anthony, D.W. 1960. Tabanidae attracted to an ultraviolet light trap. The Florida Entomologist, 43: 77-80.

Barbosa, M.G.V.; Henriques, A.L.; Rafael, J.A.; Fonseca, C.R.V. 2005. Species diversity and similarity between sites in Tabanidae (Insecta: Diptera) of a terra firme forest (Adolpho Ducke Reserve) in Central Amazonia, Brazil. Amazoniana, XVIII: 251-266 (in Portuguese, with abstract in English).

Chvála, M; Stary, P. 1967. Notes on the horse-flies of Cuba. Acta Entomologica Bohemoslovaca, 64: 392-401.

Cumming, J.M. 1992. Lactic Acid as an Agent for Macerating Diptera Specimens. Fly Times, 8: 7.

Fairchild, G.B. 1953. Arboreal Tabanidae in Panama. Proceedings of the Entomological Society of Washington, 55: 238-243.

Fairchild, G.B. 1981. Tabanidae, p. 452-460. In: Hurlbert, S.H.; Rodriguez C.; Santos, N.D. (Eds.), Aquatic Biota of South America, Part 1, Arthropoda. San Diego State University, San Diego, CA, USA.

Fairchild, G.B. 1986. The Tabanidae of Panama. Contributions of the American Entomological Institute, 22: 1-139.

Frost, S.W. 1951. Tabanidae attracted to light. Journal Series of the Pennsylvania Agricultural Experiment Station, 1714: 124-125.

Gorayeb I.S. 1999. Tabanidae (Diptera) of the Amazon. XIV. Vertical stratification in an eastern amazonian forest. Memoirs on Entomology, International, 14: 367-386.
Henriques, A.L. 2004. Tabanidae (Insecta: Diptera) from Parque Nacional do Jaú. II. Chapter 9, p: 143-152. In: Borges, S.H. et al. Windows for Biodiversity in Parque Nacional do Jaú: a strategy for the study of biodiversity in the Amazon. Fundação Vitória Amazônica, Manaus, Amazonas (in Portuguese).

Henriques, A.L.; Rafael, J.A. 1999. Tabanidae (Diptera) from Parque Nacional do Jaú, Amazonas, Brazil, with description of two new species of Diachlorus Osten Sacken. Memoirs on Entomology International, 14: 194-222.

Martins, U.R.; Galileo M.H.M.; Santos-Silva A.; Rafael J. A. 2006. Cerambycidae (Coleoptera) collected with light trap at 45 meters height over an Amazon forest canopy and the description of four new species. Acta Amazonica, 36: 265-272 (in Portuguese, with abstract in English).

McAlpine, J.F. 1981. Morphology and terminology - Adults [Chapter] 2, p: 9-63. In: McAlpine, J.F.; Peterson, B.V.; Shewell, G.E.; Teskey, H.J.; Vockeroth, J.R.; Wood, D.M. (Coords.), Manual of Nearctic Diptera, Volume 1 (Monograph 27). Research Branch, Agriculture Canada, Canada.

Pechuman, L.L.; Teskey, H.J. 1981. Tabanidae [Chapter] 31, p: 463-478. In: McAlpine, J.F.; Peterson, B.V.; Shewell, G.E.; Teskey, H.J.; Vockeroth, J.R.; Wood, D.M. (Coords.) Manual of Nearctic Diptera, Volume 1 (Monograph 27). Research Branch, Agriculture Canada, Canada.

Philip, C.B. 1982. Tabanidae (Diptera) attracted to artificial lights in California. Pan-Pacific Entomologist, 58: 365-366.

Rafael, J.A.; Gorayeb, I.S. 1982. Tabanidae (Diptera) from Amazon, I - a new suspendable trap and the first records of horse-flies from canopy trees. Acta Amazonica, 12: 232-236 (in Portuguese, with abstract in English).

Roberts, R.H.1976. Altitude Distribution of Tabanidae as determined by Malaise Trap Collections. Mosquito News, 36: 518-520.

Scherer, R.T. 2009. Description of larvae, pupae, male adult and immature bionomics of Catachlorops rufescens (Fabricius, 1805) (Diptera: Tabanidae) collected in small streams in Central Amazon, Amazonas, Brazil. Master dissertation, Instituto Nacional de Pesquisas da Amazônia/Fundação Universidade do Amazonas, Manaus, Amazonas. 98 pp. (in Portuguese).

Sinclair, B.J.; Cumming, J.M.; Wood, D.M. 1993. Homology and phylogenetic implications of male genitalia in Diptera - lower Brachycera. Entomologica Scandinavica, 24: 407-432.

Townes, H. 1972. A ligth-weigth Malaise trap. Entomological News, 83: 239-247.

Wilkerson, R.C.; Fairchild, G.B.1985. A checklist and generic key to the Tabanidae (Diptera) of Peru with special reference to the Tambopata Reserved Zone, Madre de Dios. Revista Peruana de Entomologia, 27: 37-53.

Recebido em 11/11/2009 Aceito em 27/01/2010 